\title{
TO STUDY THE ROLE OF ECHOCARDIOGRAPHY IN DETECTING VARIOUS CARDIAC CHANGES IN CHRONIC KIDNEY DISEASE
}

\author{
Prem Singh ${ }^{1}$, Reena Singh ${ }^{2}$, Rajeev Gupta ${ }^{3}$, S. K. Gautam 4 , Brijesh Kumar ${ }^{5}$
}

${ }_{1}^{1}$ Associate Professor, Department of Medicine, KPS Institute of Medicine, LLR Hospital, Kanpur, Uttar Pradesh, India. ${ }^{2}$ Associate Professor, Department of Medicine, KPS Institute of Medicine, LLR Hospital, Kanpur, Uttar Pradesh, India. ${ }^{3}$ Assistant Professor, Department of Medicine, KPS Institute of Medicine, LLR Hospital, Kanpur, Uttar Pradesh, India. ${ }^{4}$ Associate Professor, Department of Medicine, KPS Institute of Medicine, LLR Hospital, Kanpur, Uttar Pradesh, India. ${ }^{5}$ Associate Professor, Department of Medicine, KPS Institute of Medicine, LLR Hospital, Kanpur, Uttar Pradesh, India.

\section{ABSTRACT}

\section{BACKGROUND}

Chronic kidney disease (CKD) is a major public health problem worldwide with increasing incidence and prevalence. Diabetes and hypertension are the leading cause of CKD worldwide, whereas hypertension is a cause as well as effect of CKD.

Aim- To compare the cardiac function in hypertensive and normotensive CKD patients with normal subjects.

\section{MATERIALS AND METHODS}

This is a descriptive comparative study. End stage renal disease (ESRD) patients who were at stage III - V and on maintenance dialysis were subjected to 2D echo for determining various cardiac changes during the period of 1 st January 2014 to $31^{\text {st }}$ December 2014 in the Department of Medicine of GSVM Medical College, Kanpur and were included in the study. Patients with clinical evidence of coronary artery diseases, valvular heart disease, congenital heart disease and pericardial effusion were excluded from the study.

\section{RESULTS}

Out of 42 ESRD patients, $72 \%$ showed diastolic dysfunction, $60 \%$ showed left ventricular hypertrophy and global wall hypokinesis in 52\%. Other echocardiography findings were pericardial effusion in 36\% and LA is enlarged in 36\%. Clinically, there was no valvular involvement, but by echocardiography, mitral regurgitation was most commonly involved ( $p<0.01$ ). Next were tricuspid valve $(\mathrm{p}<0.01)$ and aortic valve was common $(36 \%)$. There were no severe regurgitant lesions and involvement of pulmonary valve.

\section{CONCLUSION}

Cardiac structural as well as functional abnormalities are common in patients of CKD, more in hypertensive than in normotensive patients. Diastolic dysfunction is the commonest cardiac abnormality followed by LVH. Echocardiography is cost effective and is a non-invasive diagnostic test for asymptomatic CKD patients, especially in hypertensives. This is important for early preventive measures and to check progress of the disease.

\section{KEY WORDS}

Echo, ESRD, CKD, Hypertension.

HOW TO CITE THIS ARTICLE: Singh P, Singh R, Gupta R, et al. To study the role of echocardiography in detecting various cardiac changes in chronic kidney disease. J. Evolution Med. Dent. Sci. 2018;7(24):2838-2841, DOI: 10.14260/jemds/2018/640

\section{BACKGROUND}

Cardiovascular disease is a leading cause of morbidity and mortality in patients at every stage of chronic kidney disease. $30 \%-45 \%$ of patients reaching stage 5 chronic kidney disease already have developed cardiovascular complications. According to NKF guidelines, CKD defined as either (1) Kidney damage for $>3$ months as confirmed by kidney biopsy or markers of kidney damage with or without a decrease in glomerular filtration rate (GFR) or (2) GFR $<60$ $\mathrm{mL} / \mathrm{min} / 1.73 \mathrm{~m} 2$ for $>3$ months with or without kidney damage. Kidney damage is ascertained by either kidney biopsy or markers of kidney damage such as proteinuria, urinary sediment or abnormalities on imaging studies.

'Financial or Other Competing Interest': None.

Submission 30-01-2018, Peer Review 25-05-2018,

Acceptance 31-05-2018, Published 11-06-2018.

Corresponding Author:

Dr. Reena Singh,

L-14, GSVM Medical College Campus,

Kanpur, Uttar Pradesh,

India.

E-mail: dr.10reenasingh@gmail.com

DOI: $10.14260 /$ jemds $/ 2018 / 640$

\section{(c) $($ ) $\odot$}

The finding of proteinuria not only defines the presence of CKD, but also has important implications for diagnosis of the type of kidney disease and is associated with a worse prognosis for both kidney disease progression and the development of CVD.

Measurement of albumin-to-creatinine ratio or total protein-to-creatinine ratio in untimed "spot" urine samples is recommended for assessment of proteinuria. GFR $<60$ $\mathrm{mL} / \mathrm{min} / 1.73 \mathrm{~m} 2$ is selected as the cut-off value for definition of CKD, because it represents a reduction by more than half of the normal value of $125 \mathrm{~mL} / \mathrm{min} / 1.73 \mathrm{~m} 2$ in young men and women and this level of CRF is associated with the onset of laboratory abnormalities characteristic of kidney failure, increased prevalence and severity of several CVD risk factors.

Kidney failure is defined as GFR $<15 \mathrm{~mL} / \mathrm{min} / 1.73 \mathrm{~m} 2$ or treatment by dialysis in CKD. It is useful to consider 2 subtypes of arterial vascular disease namely atherosclerosis and large vessel remodelling of arteriosclerosis. Atherosclerosis is an intimal disease characterised by the presence of plaques and occlusive lesions. There is a high prevalence of atherosclerosis in CKD. Atherosclerotic lesions in kidney failure are frequently calcified as opposed to fibromatous include both intima media thickness of the 
carotid wall. Dialysis patients with ischaemic heart disease may not necessarily have large vessel coronary disease. The patients may have ischaemia secondary to the combined effects of volume overload and left ventricular hypertrophy (LVH), which causes increased oxygen demand and small vessel coronary disease which causes decreased oxygen supply. Patients with CKD also have a high prevalence of arteriosclerosis and remodelling of arteries. Remodelling may be due to either pressure overload with an increased wall to lumen ratio or flow overload which is characterised by a proportional increase in arterial diameter and wall thickness. Remodelling often accompanies a reduction in arterial compliance, which can be detected through measurement of aortic pulse wave velocity and characteristic impedance. Noncompliant vessels may result in increased systolic blood pressure, increased pulse pressure, LVH and decreased coronary perfusion. Both decreased aortic compliance and increased pulse pressure have been found to be independent risk factors for CVD in dialysis patients. Patient with CKD also have a high prevalence of cardiomyopathy.

Hypertension and arteriosclerosis result in pressure overload and lead to concentric LHV (increased wall to lumen ratio), whereas anaemia, fluid overload and arteriovenous fistulas result in volume overload and primarily lead to left ventricular dilatation with LVH (a proportional increase in left ventricular mass and diameter). These structural abnormalities may lead to diastolic and systolic dysfunction. These dysfunctions may be detected by echocardiography, so periodic echo is recommended. This study is to assess the role of detecting various cardiac changes in CKD.

\section{Objective}

To compare the cardiac function in hypertensive and normotensive CKD patients with normal subjects.

\section{MATERIALS AND METHODS}

This study is a descriptive comparative study. All patients of CKD attending OPD/ Nephrology clinic and admitted in indoor in LLR Hospital, Department of Medicine, GSVM Medical College, Kanpur during the period of January 2014 to December 2014 in the Department of Medicine were included in this study. 13 controls were selected from healthy to standardised various echocardiographic parameters of cardiac functions. Patients were grouped under 3 groups.

\section{Group A}

Normal healthy controls.

\section{Group B}

Established cases of chronic renal failure on conservative treatment or going for haemodialysis with normal blood pressure 20 cases.

\section{Group C}

Established cases of chronic renal failure patients and conservative treatment or going for haemodialysis with hypertension 22 cases.

\section{Sample Size}

It was calculated using the formula for calculation of sample size for the difference in two means.

\section{Formula}

At power $=80 \%$ and $\mathrm{x}=5 \%$

$N=\left[\left(Z_{\alpha / 2}+Z_{\beta}\right)^{2} \times\left\{2(\sigma)^{2}\right] /\left(\mu_{1}-\mu_{2}\right)^{2}\right.$

\section{Where}

$\left(\mathrm{Z}_{\alpha / 2}+\mathrm{Z}_{\beta}\right)^{2}=7.84$

$\sigma=$ Standard deviation

$\mu_{1}=$ mean of group 1

$\mu_{2}=$ mean of group 2

A Pilot Study was done on 5 subjects in < groups each

Group 1= Normal subjects $=\mathrm{EF}=62.45 \pm 2.45$

Group 2= Normotensive CRF patients

$\mathrm{EF}=59.65 \pm 2.6$

\section{Hence Taking, \\ $\sigma=2.45$ \\ $\mu_{1}=62.45$ \\ $\mu_{2}=59.65$ \\ $\mathrm{N}=7.84 \times 2 \times(2.45)^{2} /(2.8)^{2}$ \\ $=12$ in each group calculated as 12 . \\ Exclusion Criteria disease. \\ 2. Rheumatic heart disease. \\ 3. Cardiomyopathy. \\ 4. Ischaemic heart disease. \\ 5. Heart failure. \\ 6. Patients with diabetes.}

Therefore, minimum sample size in each group was

1. The following patients were excluded from the study with pre-existing cardiac disease like congenital heart

All the patients who were included in the study were subjected to investigate like complete haemogram, renal function test, serum electrolytes, blood glucose level, lipid profile, urine examination, echo, chest x-ray and ultrasound KUB region and ECHO.

2D echocardiography Hewlett Packard SONU S 2000 ultrasound was used for evaluation of cardiac changes. Patients were examined in supine and left lateral position using all 4 basic echocardiography windows. AO, LA, LVID, LVIDs, LVPWd, LVPWs, IVSd, IVSs, LVM, EF, RWMA, pericardial effusion and Doppler study across valves were measured.

\section{Statistical Analysis}

Data was compiled and analysed using SPSS 18.0 . Comparison between three groups was done using one-way ANOVA with post hoc test. $\mathrm{P}$ value less than 0.05 was considered significant.

\section{RESULTS}

In the present study, cardiovascular involvement was studied in 42 patients of CKD during the period of January 2014 to December 2014 in the LLR Hospital in Department of Medicine. The observation made were as follows. The age of the patients in the present study ranged from 30 years to 80 years. The mean age was $47.58+15.3$ years with male: female ratio of 2: 1 . 


\begin{tabular}{|c|c|c|c|c|c|c|c|}
\hline S1. No. & $\begin{array}{c}\text { Group A } \\
\text { Control }\end{array}$ & $\begin{array}{c}\text { Group B } \\
\text { Normotensive }\end{array}$ & $\begin{array}{c}\text { Group Cypertensive } \\
\text { Hyper }\end{array}$ & $\begin{array}{c}\text { Age } \\
\text { Group }\end{array}$ \\
\hline 1 & M & F & M & F & M & F & Patients \\
\hline 2 & 2 & 1 & 1 & 0 & 1 & 1 & $30-39$ \\
\hline 3 & 3 & 1 & 6 & 3 & 6 & 3 & $40-49$ \\
\hline 4 & 3 & - & 6 & 3 & 6 & 3 & $50-59$ \\
\hline 5 & 1 & 1 & 1 & 1 & 1 & 1 & $60-69$ \\
\hline 6 & - & 1 & - & - & - & - & $70-79$ \\
\hline Table 1. Distribution of Study Subjects based on Age and \\
Gender \\
\hline
\end{tabular}

\begin{tabular}{|c|c|c|}
\hline \multicolumn{3}{|c|}{ Type of Management } \\
\hline Dialysis & Number & Percent \\
\hline On Dialysis & 35 & $85 \%$ \\
\hline Not on Dialysis & 7 & $15 \%$ \\
\hline Total & $\mathbf{4 2}$ & $\mathbf{1 0 0} \%$ \\
\hline Table 2. Distribution of Patients based on Dialysis \\
\hline
\end{tabular}

\begin{tabular}{|c|c|c|c|c|}
\hline \begin{tabular}{|c|} 
Echo \\
Cardiographic \\
Parameters
\end{tabular} & $\begin{array}{c}\text { Group A } \\
\text { Control } \\
\text { Mean } \pm \\
\text { SD }\end{array}$ & $\begin{array}{c}\text { Group B } \\
\text { Hypertensive } \\
\text { CRF } \\
\text { Mean } \pm \text { SD }\end{array}$ & \begin{tabular}{|c|} 
Group C \\
Normo- \\
tensive \\
CRF \\
Mean \pm SD
\end{tabular} & $\begin{array}{c}\text { 'p' } \\
\text { value }\end{array}$ \\
\hline $\mathrm{AO}(\mathrm{cm})$ & $\begin{array}{c}3.01 \pm \\
0.25\end{array}$ & $3.03 \pm 0.22$ & $\begin{array}{l}3.01 \pm \\
0.361\end{array}$ & 0.9648 \\
\hline $\mathrm{LA}(\mathrm{cm})$ & $\begin{array}{c}3.05 \pm \\
0.34\end{array}$ & $3.78 \pm 0.34$ & $3.63 \pm 0.24$ & $<0.0001$ \\
\hline LVIDd & $\begin{array}{c}4.76 \pm \\
0.44\end{array}$ & $5.21 \pm 0.68$ & $4.85 \pm 0.70$ & $<0.0941$ \\
\hline LVIDs (cm) & $\begin{array}{c}3.42 \pm \\
0.54\end{array}$ & $3.84 \pm 0.74$ & $3.49 \pm 0.05$ & $<0.0400^{*}$ \\
\hline LVPWd (cm) & $\begin{array}{c}0.92 \pm \\
0.15\end{array}$ & $1.10 \pm 0.22$ & $1.05 \pm 0.22$ & 0.0546 \\
\hline LVPWs (cm) & $1.5 \pm 0.16$ & $1.43+$ & $1.40 \pm 0.16$ & 0.4222 \\
\hline LVPWs (cm) & $\begin{array}{c}092 \pm \\
0.15\end{array}$ & $1.10 \pm 0.24$ & $1.03 \pm 0.28$ & $0.0001 *$ \\
\hline IVSs $(\mathrm{cm})$ & $1.5 \pm 0.16$ & $1.43 \pm 0.25$ & $1.40 \pm 0.25$ & 0.4715 \\
\hline LVM (gm) & $120 \pm 13$ & $228 \pm 44$ & $167 \pm 20$ & $0.0001^{*}$ \\
\hline EF (\%) & $\begin{array}{c}62.30 \pm \\
2.45\end{array}$ & $56.83 \pm 4.77$ & $60 \pm 3.49$ & $0.0006^{*}$ \\
\hline
\end{tabular}

* LA- Group A and B - p value $<0.001$ significant.

* LA- Group A and C - p value $<0.001$ significant.

** LVPWs- Group A and B - p value $<0.001$ significant.

** LVPWs- Group A and C - p value $<0.001$ significant.

*** LVM- Group A and B - p value $<0.001$ significant.

*** LVM - Group A and C - p value $<0.001$ significant.

*** LVM - Group B and C - p value $<0.001$ significant.

$* * * *$ Ef - Group A and B - p value $<0.001$ significant.

$* * * *$ Ef - Group B and C - p value $<0.05$ significant.

\begin{tabular}{|c|c|c|}
\hline & $\mathbf{N = 4 2}$ & $\mathbf{9}$ \\
\hline LVH & 15 & $60 \%$ \\
\hline LA Early & 9 & $36 \%$ \\
\hline Diastolic dysfunction & 18 & $72 \%$ \\
\hline Pericardial effusion & 9 & $36 \%$ \\
\hline Global Wall Hypertensive & 13 & $52 \%$ \\
\hline $\begin{array}{c}\text { Clot thrombus, valve thickening, } \\
\text { calcification }\end{array}$ & 0 & 0 \\
\hline Regional Wall Motion & 0 & 0 \\
\hline
\end{tabular}

\begin{tabular}{|c|c|c|}
\hline Abnormality & & \\
\hline $\begin{array}{l}\text { Asymmetrical Septal } \\
\text { Hypertrophy }\end{array}$ & 0 & 0 \\
\hline Involvement & 4 & 16 \\
\hline Mitral Valve & 19 & 76 \\
\hline Tricuspid Valve & 10 & 40 \\
\hline Aorta & 4 & 16 \\
\hline
\end{tabular}

\begin{tabular}{|c|c|c|c|c|}
\hline \begin{tabular}{|l} 
Sl. \\
No.
\end{tabular} & Parameters & $\begin{array}{c}\text { Clinical } \\
\text { Detection }\end{array}$ & $\begin{array}{c}\text { Echocardiographic } \\
\text { Detection }\end{array}$ & $\%$ \\
\hline & $\begin{array}{c}\text { Valve } \\
\text { Involvement } \\
\text { Mitral }\end{array}$ & 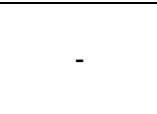 & 19 & $76 \%$ \\
\hline & Tricuspid & - & 10 & $40 \%$ \\
\hline & Aortic & - & 4 & $16 \%$ \\
\hline
\end{tabular}

Out of 42 cases $72 \%$ showed diastolic dysfunction, $60 \%$ showed left ventricular hypertrophy and global wall hypertension in 52\%. Other echocardiography findings were pericardial effusion 36\%. LA enlarge 36\%. Clinically, there was no valvular involvement, but by echocardiography mitral regurgitation was most commonly involved. Next were tricuspid valve and aortic valve. Out of regurgitate lesions, mild MR was most common (36\%). There were no severe regurgitate lesions and involvement of pulmonary valve.

\section{DISCUSSION}

Premature cardiovascular disease is a significant cause of morbidity and mortality among patients with CKD. Premature atherosclerotic coronary disease is driven by multiple risk factors including dyslipidaemia and oxidative stress. Four main structural abnormalities of the heart have been described in patients with CKD. LV hypertrophy, expansion of the non-vascular cardiac interstitium leading to intermyocardiocytic fibrosis, changes in vascular architecture and myocardial calcification. All these abnormalities promote systolic as well as diastolic LV dysfunction which predisposes to symptomatic heart failure, which in turn is a risk factor for premature death. Echocardiography can detect cardiac changes in early stages.

Echocardiography is safe, simple and sensitive method to detect small pericardial effusion, helping to analyse the cause of chest pain and cardiomegaly and thus guide anticoagulant therapy patients who are on haemodialysis.

Early detection and treatment of major cardiac complications in patients of chronic renal failure may change the outcome.

This study consisted of 42 patients of chronic renal failure. Male and female ratio is 2:1 in my study which is comparable with Owen et al,[1] who found it to be $2: 1$ and study of Ladda et al[2] found that male-to-female ratio was 3.

In my study out of 42 patients overall diastolic dysfunction was present in $72 \%$, which is comparable with NP Singh et al (2000) ${ }^{[3]}$ who found diastolic dysfunction in $72 \%$, S Agarwal et al (2003) ${ }^{[4]}$ observed diastolic dysfunction in $60 \%$ and Mukesh et al (2014) found diastolic dysfunction in $61.2 \%$. In my study, diastolic dysfunction was $86.6 \%$ in hypertensive and $50 \%$ in normotensive group.

There was statistically significant association between the finding of 2D echo in patients having hypertension as compared to normotensive group for abnormal E/A ratio. 
LVH was present in $60 \%$ cases. Robert N Foley et al (1995) ${ }^{[5]}$ found $\mathrm{LVH}$ in $73.9 \%$ cases, NP Singh et al found $\mathrm{LVH}$ in $76.92 \%$ and Zoccali et al (2000)[6] found in $77 \%$. In intergroup comparison, hypertensive patients had larger left ventricular mass as compared to normotensive group $(\mathrm{p}<.05)$. In my study pericardial effusion was present in $36 \%$ patients which is consistent with a study of Meon et al (1988) who reported 32\% incidence, Achari et al (1989)[7] reported $50 \%$ incidence, while Barrionuevo AJD et al (2010)[8] found in $65 \%$ cases and Laddha et al found in $14-30 \%$ cases. In present study, global wall hyperkinesia was present in $52 \%$ cases. In contrast Goornavar SM et al (2015) ${ }^{[9]}$ showed $16 \%$, Parfrey et al[10] reported $20 \%$ and $25 \%$ in the study of Greaves et al.[11] RWMA is not found in my study. Calcification of heart valves were not present clinically. There was no valvular involvement, but by echocardiography mitral regurgitation was most commonly involved ("p" $<0.001$ ), next were tricuspid valve ("p" $<0.001)$ and aortic valve ("p" $<$ 0.001). Out of regurgitant lesions, mild MR was most common. There was no severe regurgitant lesions and involvement of pulmonary valve.

$16 \%$ of CRF patients have hyperdynamic left ventricle and $8 \%$ of CRF patients had low cardiac output failure. LA enlargement was seen by echo in $36 \%$ cases, which was statistically significant $(\mathrm{p}<5.00)$.

\section{CONCLUSION}

Cardiac structural as well as functional abnormalities are common in patient of CKD, more in hypertensive than in normotensive patients.

Diastolic dysfunction is the commonest cardiac abnormality followed by LVH. Echocardiography is cost effective and a non-invasive diagnostic test for asymptomatic CKD patients, especially in hypertensives. This is important for early preventive measures and in checking prognosis of the disease.

\section{REFERENCES}

[1] Owen WF, Madore F, Brenner BM. An observational study of cardiovascular characteristics of long term end-stage renal disease survivors. American Journal of Kidney Diseases 1996;28(6):931-6.
[2] Laddha M, Sachdeva V, Diggikar PM, et al. Echocardiographic assessment of cardiac dysfunction in patients of end stage renal disease on haemodialysis. JAPI 2014;62(1):28-32.

[3] Singh NP, Chandrashekar, Nair $M$, et al. The cardiovascular and hemodynamic effects of erythropoietin in CRF. JAPI 2000;48(3):301-6.

[4] Agarwal S, Dangri P, Kalra OP, et al. Echocardiographic assessment of cardiac dysfunction in patients of chronic renal failure. JIACM 2003;4(4):296-303.

[5] Foley RN, Parfrey PS, Harnett JD, et al. Clinical and echocardiographic disease in patients starting end stage renal disease therapy. Kidney Int 1995;47(1):186-92.

[6] Zoccali C, Benedetto FA, Mallamaci F, et al. Prognostic value of Echocardiographic indications of left ventricular systolic function in asymptomatic dialysis patients. J Am Soc Nephrol 2004;15(4):1029-37.

[7] Achari V, Thakur AK. Echocardiographic detection of cardiac involvement in chronic renal failure. JAPI 1989;37(7):434-6.

[8] Barrionuevo AJD, Vargas-Machuca GMF, Pulido FG, et al. Transthoracic echocardiographic findings in patients with chronic kidney disease awaiting kidney transplantation. Transplantation Proceedings 2010;42(8):3123-5.

[9] Goornavar SM, PramilaDevi R, Ashoka RM. A study of echocardiographic changes in patients with chronic kidney disease. Medica Innovatica 2015;4(2):1-5.

[10] Parfrey PS. Cardiac and cerebrovascular disease in chronic uremia. American Journal of Kidney Diseases 1993;21(1):77-80.

[11] Greaves SC, Gamble GD, Collins JF, et al. Determinants of left ventricular hypertrophy and systolic dysfunction in chronic renal failure. American Journal of Kidney Disease 1994;24(5):768-76. 